\title{
Springets koloniale globalisering - om bevægelseskultur i Rwanda
}

\section{Af Henning Eichberg}

John Bale, Imagined Olympians: Body Culture and Colonial Representation in Rwanda, University of Minnesota Press (Minneapolis, 2002). 228 s., \$19,95.

Da rejsende fra Europa i begyndelsen af 1900-tallet kom til Rwanda i Centralafrika, opdagede de noget bemærkelsesværdigt. De mødte slanke, høje, smukke unge mænd, som ved bestemte lejligheder sprang højt over andre menneskes hoveder. Det koloniale Europa stirrede med forundring og tog fotografier af denne eksotiske begivenhed. Det sportive Europa begyndte at måle de såkaldte watussi-springeres resultater og spekulere over deres fremtidige olympiske rekordmuligheder. Men på de olympiske resultatlister dukkede aldrig en eneste af watussierne op. De kom derimod på andre måder i verdens søgelys: Watussier - eller tutsier, som de også hed - er stødt sammen med hutuer i voldelige uroligheder siden 1959. I 1994 blev Rwandas tutsi-befolkning offer for et af de mest forfærdelige massedrab i vor tid. Mellem en halv og en million mennesker mistede livet.

Man kan i første omgang godt synes, at højdespringet i Rwanda er et meget specielt og måske lidt bizart emne. Men John Bale har fremlagt en velskrevet bog om disse springere, »Imagined Olympians «, som viser, hvordan man ud fra en konkret kropslig aktivitet kan oplyse om omfatten- de sammenhænge. Bogen fortæller om kolonialisme, olympisk sport og folkemord om grundlæggende identitetsspørgsmål i en globaliserende verden.

\section{Hoffets springende elitehold}

Forud for den koloniale underkastelse var Rwanda et kongerige med et folk, som bestod af en snes klaner. Hver klan var sammensat af tre forskellige sociale statusgrupper - tutsier, hutuer og twaer.

Tutsierne udgjorde et mindretal på 15\% og betragtedes som overlegne, fordi de stammede fra himlen. De var overvejende kvægavlere, havde en krigerisk selvforståelse og stillede det regerende dynasti omkring »kongen «. Imidlertid var ikke alle tutsier aristokrater, nogle var fattigere end hutuer, og når en tutsi for alvor tabte status, kunne han selv blive betragtet som hutu. Hutuerne udgjorde befolkningens flertal med over $80 \%$ og regnedes som underordnede. De var overvejende agerdyrkere. Men hvis en hutu blev rig, kunne han også blive tutsi. En mindre gruppe - omkring $1 \%$ - udgjordes af twaerne, også kaldet buskmænd eller pygmæer. De regnedes som endnu lavere i status og var jægere og samlere.

De tre statusgrupper levede i samfundsmæssig vekselvirkning med hinanden, og deres klaner var, som sagt, blandet. Hutuer og tutsier talte et fælles sprog, en under- 
gruppe af bantu-sproget kiswahili. Og de havde en fælles kultur.

Rwandas komplekse gruppehierarki var altså præget af elitisme, kvæg som rigdom, krigervæsen, oprindelsesmyter - og gensidigt samvirke. Samfundet var spændingsfyldt, det var ingen idyl. Men der var samspil.

Kongens hof var en forsamling af flere 1000 mennesker - adelsfolk, tjenere og andre - som periodisk rejste fra sted til sted for at vise kongedømmets rituelle magt. Ved dette hof fandtes også en gruppe af et par 100 unge mænd, som levede sammen og fik en fælles træning, bestående af digterkunst og dans, selvforsvar og kamp, spydkast, $l \varnothing b$ og spring. Elitegruppens værdier var præget af mandighed, trofasthed mod tronen, krigeriske kvaliteter og selvbeherskelse. De fleste medlemmer var tutsier, men en mindre gruppe var hutuer, enkelte måske også twaer.

Denne udvalgte gruppe blev brugt til festlige lejligheder, hvor de dansede og viste andre kunstarter frem. Det skete ved disse ceremonielle situationer, at vestlige rejsende fra 1907 og frem til 1950'erne mødte det berømte højdespring - nogle gange med flere 1000 af tilskuere som kulisse. Spring øvelsen var en rituel opvisning inden for rammerne af en fest. Man sprang med afsæt på en sten eller et termitbo og højt over et stativ. Springet blev gerne vist af en hel gruppe af unge mænd, som fulgte i tæt opløb efter hinanden. Men de bedste springeres navne var kendt i befolkningen og kunne huskes helt op til 1970'erne.

\section{Spring, som ikke er sport}

Da det koloniale overherredømme over landet efter 1885 blev etableret i tysk regi, bestod det i første omgang af forholdsvist få rejsende, missionærer og officerer. Ko- loniseringsprocessen blev strammet op af den belgiske besættelsesmagt, som overtog Rwanda i 1916. Blandt de tidligere tyske rejsende var hertug Adolf Friedrich von Mecklenburg, som under sin ekspedition i 1907 mødte højdespringet og lod det fotografere. Dermed fremlagde han den klassiske dokumentation om højdespringet $\mathrm{i}$ Rwanda, som siden igen og igen er blevet reproduceret i litteraturen.

De fleste vestlige rejsende beskrev springøvelsen mere eller mindre naivt som »højdespring « og »sport«. På sportiv vis var der tale om $\gg$ Rwandas champion-springere«, og termitstenen kaldtes for et »springbræt«. Man målte springernes »rekorder«, sammenlignede dem med den vestlige sports rekorder og forestillede sig springerne som fremtidens olympiske atleter.

Afvigende fra dette sportive sprog var der imidlertid også enkelte rejsende, som beskrev begivenhederne ved det rwandiske hof - spring i sammenhæng med dans og »pantomime« - som »underholdning $«$, »opvisning « eller »fest«, i enkelte tilfælde endnu mere passende som »traditionel kunst « og som »springkunstnere«. Det lokale sprog kom i hvert fald ikke til orde, her hed springet gusimbuka urukiramende: at springe over tværbjælken, over stativet.

Springøvelsen blev i den følgende tid til en arena, hvor kolonisationen viste sig som en række af konflikter. Som det første blev vestlig kolonial sport importeret i 1920'erne, især gennem de belgisk-katolske missionsskoler. Den mest populære sport blev efterhånden fodbold. I dag er Rwanda en del af det globale sportssystem, og landets atleter konkurrerer på topplan især ved $l \varnothing b$ over mellem- og langdistancer. Gusimbuka blev aldrig inddraget $\mathrm{i}$ dette koloniale sportssystem.

I samme tidsrum, da den koloniale sport 
ekspanderede, blev elitegruppen ved hoffet omformet. Først tvang kolonistyret kongen til at nedlægge gruppen helt, den blev betragtet som »hedensk « og - på grund af sin krigeriske moral - farlig. Men senere blev gruppen videreført med tilknytning til den katolske missionsskole og til sidst reduceret til en dansegruppe - Royal Watussi Dancers.

Det sidste skub skete gennem de postkoloniale massakrer i Rwanda. Belgiens indirekte styre havde brugt og misbrugt tutsimagten som led i en kolonial politik af »del og hersk«. Men i 1950'erne begyndte hutu-intellektuelle at stille krav om demokrati, og i 1959 var der oprør imod lokale tutsi-høvdinge. I 1961 blev monarkiet afskaffet, kongen flygtede, og mange tutsier blev myrdet. Dermed forsvandt gusimbuka fra landkortet. Med Rwandas uafhængighed i 1962 etableredes en hutu-magt, og i 1994 slog hutu-ekstremister løs med omfattende folkedrab på tutsierne og de moderate hutuer.

I sammenhæng med disse massakrer blev det af og til berettet, at hutuer i enkelte tilfælde skar tutsieres akillessener over eller endog hakkede ligenes ben af. Dette kropslige udtryk for kampen imod »de store« kan man læse som et blodigt slutpunkt for det berømte højdespring i Rwanda.

\section{Kolonialt kamera og sportiv rekord}

Hvilken rolle spillede det vestlige blik, som rettede sig mod gusimbuka, for denne tragedie mellem folkegrupperne? Sådan spørger John Bale i sin undersøgelse. Ved nærmere betragtning kan Bale identificere fire strategier for det koloniale blik, som delvist modsiger hinanden: kontrol, tilpasning, idealisering og negation:
1. Kontrol: Det anderledes skal overvåges. Når den vestlige betragter mødes med noget så uforståeligt som gusimbuka, skal det under kontrol, og derfor måles og registreres rekorder. For den koloniale betragter indgik gusimbuka i rekordens »objektive« præstationsregnskab.

2. Tilpasning: Det fremmede skal underkastes betragterens egne kategorier, for at man bedre kan forstå og kontrollere det. Tilpasningen sker bl.a. gennem navngivning: Gusimbuka er en »sport« med »springbræt «, $\quad$ »rekorder «, $\gg$ champions«, imaginerede »olympiske atleter « etc. Navnet fungerer som en form for magtudøvelse. Betegner man gusimbuka som »sport«, betyder det, at man principielt ikke anerkender den anderledes kropskultur: Alt er lige, og det er os vesterlændinge, der har det passende ord - det er os, der har ordet.

3. Idealisering: Det fremmede kan også romantiseres. Springerne fra Rwanda fremkalder beundring. De blev omtalt som »beundringsværdige «, »graciøse « og »naturlige «, og man roste deres »perfekte, slanke gestalt $\ll$. Den smidige, smukke ædle watussi-atlet var en variant af »den ædle vilde«, med æstetiske og (homo)erotiske undertoner.

4. Negation: Det, som i første omgang virker imponerende, bliver imidlertid også ofte nægtet. Negationen er ellers den dominerende vestlige strategi over for Afrika som »tilbagestående« og »elendigt $\ll$. Men det er vanskeligt at gennemføre i forhold til det imponerende højdespring fra Rwanda, som netop ikke virkede »primitivt « eller »vildt «. Alligevel forsøgte man på mange måder at nægte, formindske eller nedvurdere mesterskabet. Tutsiernes spring blev tilskrevet en slags freak-kvalitet, og titler som »the jumping giants of Rwanda« minder om 
fantasinegeren fra Tarzan-tegneserien. De blev betragtet som »dovne« i overensstemmelse med stereotypen om den utrænede »naturlige atlet «. Og gusimbukas »rekorder « blev gennem en nøjeregnende kildekritik helt afvist.

Kilder - både beretninger og de »objektive « fotografier - fortæller mere om iagttageren end om selve »sagen «. Når man med en finger viser frem, så viser tre fingre tilbage - det er et billede for den (selv)kritiske etnocentrisme, som John Bale afprøver.

\section{Hvem er springets folk?}

Gennem dybdeanalyse lykkes det altså for John Bale at stille spørgsmål ved grundlæggende begreber som højdespring, sport, springbræt og atlet. Kategorierne er ikke uskyldige. Men den postkoloniale kritik fører videre: Det er heller ikke uskyldigt at sige »tutsi« eller »hutu« og at omtale dem som etnisk gruppe, kaste, stamme, race eller social klasse.

Springet i Rwanda fortæller også om, hvem der springer - om springets folk. Det fortæller om, hvordan det koloniale blik konstruerede de tre etniske grupper tutsi, hutu og twa og forholdt sig selv (som »hvid «) til dem.

I Rwanda mødte man i gestalt af hoffets dansere og springere stolte mennesker, som viste en overlegen præstation og ellers optrådte hemmelighedsfuldt og nedladende, nogle gange direkte arrogant over for europæerne. Disse afrikanere repræsenterede ikke den type »negre«, som man ellers troede at møde. Hvordan kunne man klare denne udfordring, som inderst inde truede ens egen koloniale identitet?

Det er på dette punkt, at vesterlandske betragtere konstruerede den hamitiske hy- potese. Det skete i en blanding af race-, sprog- og vandringsspekulationer. Tutsierne kunne ikke være »normale negre«, de måtte være kommet andre steder fra, helst fra nord. Forskellige orientalske folk i Nordafrika taler hamitiske sprog - fra Etiopien og Somalia til berberfolket. Til dem knyttede man oprindelsesfantasier om, at tutsierne måtte være indvandret fra nord. Var de egyptisk af oprindelse, måske ligefrem faraoniske efterkommere, og dermed i grunden hamitiske?

De hamitiske oprindelsesfantasier blev knyttet sammen med fysiske antagelser. Tutsierne blev set som høje og slanke, de havde smal næse, høj pande og lysere hudfarve. Dels var disse kropsstereotyper overdrevet, dels ligefrem forkerte (f.eks. hvad angår hudfarven). De kropslige forskelle blev suppleret med psykiske: Watussierne blev - til forskel for »de undersætsige, fladnæsede, uintelligente, muntre bantu-negre « - beskrevet som ærlige, pålidelige, stolte, krigeriske, som de fødte ledere. Gusimbuka dannede en synlig forbindelse mellem disse raceantagelser om krop og ånd. »Watussi er en europaer, som tilfaeldigvis har sort hud «, skrev en kolonial forfatter. Tutsi blev en hædersolympier, næsten en slags hædersarier.

Det var den koloniale identitet, som havde behov for en non-negro solution af tutsispørgsmålet og for den rigide, reificerende opdeling af »stammer « og »racer«. Både den belgiske indirect rule og den katolske mission støttede sig til tutsi-magten og promoverede derfor den hamitiske hypotese. Og i 1933 indførte kolonistyret et identitetskort, som gjorde den etniske kategorisering officiel. Tutsi-hutu-opdelingen var blevet tingsliggjort som »stamme .

Den koloniale tingsliggørelse af tutsi- og hutu-identiteten indgik i de koloniseredes subjektive bevidsthed. Den hamitiske hy- 
potese begyndte at præge tutsiernes vi-dannelse og blev til en tutsi-ideologi. Den autoritative rwandiske historiebog fortalte ud fra det tutsi-hamitiske perspektiv: $\mathrm{Vi}$ er kommet fra nord, vi er adelige, vi har bragt den royale civilisation med os... Dette smittede af på hutuernes identitets-dannelse og blev til en hutu-ideologi: »De der« er bare indvandrere fra nord og $\mathrm{i}$ grunden $\gg$ fremmede« her hos os, vi er landets egentlige indfødte... Da oprørske hutuer senere krævede demokrati, kom dette syn til udtryk. Den hamitiske hypotese slog tilbage, som fjendebillede. Den var vejen til massakren.

I hvert fald kan identity building godt bevirke det modsatte af nation building og Rwanda er et rystende eksempel på dette. Der er grund til kritisk at tage afstand fra den naive olympiske antagelse om, at sportens globalisering fører til verdensfred og folkeforsoning.

John Bale er yderst forsigtig med at tale om sportens »medskyld « i Rwandas tragedie. Han slutter med et åbent spørgsmål: $\gg$ At what point does complicity stop? «

\section{Kropskulturens trialektik}

John Bales bog Imagined Olympians, fører til en række væsentlige metodologiske konklusioner:

\section{Gusimbuka lægger på grund af sin netop} ikke-konkurrerende karakter og sin sammenhæng med dans op til en begrebsliggørelse, som ikke knytter sig til sporten. John Bale taler derfor om body culture, kropskultur.

2. Kroppen er imidlertid ikke noget entydigt. Hvordan fanger vi så menneskets kropslighed i dens flertydighed? Det kræver i hvert fald et grundlæggende opgør med kroppens tingsliggørelse. Sporten gør kropslige forhold til ting gennem resultatet, gennem rekorden (som spærrer for forståelsen af højdespringet i Rwanda). Også biomekanik og antropometri bidrager til denne tingsliggørelse. Og ikke mindst folkets indre modsætninger og komplekse vekselvirkninger bliver til ting: kulturelt som »etnisk gruppe $\ll$, biologisk som »race $\ll$, socialt som »kaste«. Man kan altså godt blive grundlæggende skeptisk over for kroppens og »sagens« autenticitet, men det betyder ikke, at alt er »bare konstrueret $«$.

3. Kropskulturen skal tænkes ud fra modsætninger. Der er hegemoni og konflikt. Modsætninger er hverken »objektive« eller »kun udtænkte«.

Til nærmere at bestemme modsigelserne omkring højdespringet i Rwanda anvender John Bale en model med tre konfigurationer: præstations-, velfærds- og folk-modellen. Gusimbuka er netop ikke et resultatspring, som vi kender fra præstationssporten. Men det er heller intet holdnings- og sundhedsspring, som gymnastik og anden velfærdssport har opdyrket. Gusimbuka hører derimod til den folkelige kropskultur, til fest og ritual, leg og dans, folkemusik og cirkus.

Kropskulturens trialektik er ikke kun analytisk, men også politisk: Kolonialismekritikken træder med globaliseringen ind $\mathrm{i}$ en ny fase. Mens globaliseringsdiskursen genopliver et endimensionalt moderniseringsbegreb, viser Rwandas case et billede af modsætninger. Set ud fra gusimbuka: Modernisering er højdespringets sportslige udvikling, også for kvindernes vedkommende - og stativspringets forsvinden. Eller mere tilspidset: Modernisering i Rwanda er sportificering plus massakre.

Og globalisering er ikke en ensrettet trafik ud i fremtiden, men et møde med nye modsigelser. 